\title{
Re-examination of the Photosynthetic Capacity of In Vitro-cultured Strawberry Plantlets
}

\author{
De Yue', André Gosselin, and Yves Desjardins \\ Département de phytologie, Centre de recherche en horticulture, Faculté des sciences de l'agriculture et \\ de l'alimentation, Université Laval, Ste-Foy, Québec, G1K 7P4, Canada \\ Additional index words: Fragaria $\times$ ananassa, micropropagation
}

\begin{abstract}
Photosynthesis and growth of in vitro-cultured strawberry plantlets (Fragaria $\times$ ananassa Duch. cv Kent) were investigated during a 4-week in vitro culture in a rooting medium and a 4-week ex vitro period. The leaves formed in vitro on a medium containing sucrose developed a positive photosynthetic capacity. At transplanting to the ex vitro environment, their photosynthetic rate was $12.76 \mu \mathrm{mol} \mathrm{CO}_{2} / \mathrm{m}^{2}$ per second, which was as high as that of leaves generated and grown in the greenhouse. During the ex vitro period, photosynthetic rates of in vitro-generated leaves decreased and dark respiration rates increased. However, in vitro leaves were photosynthetically active throughout the 4 weeks ex vitro. In the first 2 weeks of the ex vitro period, in vitro-generated leaves had an important contribution to the overall plantlets' photosynthetic capacity.
\end{abstract}

Acclimatization is a critical stage of micropropagation of many species because of poor survival after transfer to the greenhouse or field. Water stress and poor photosynthetic capacity are the two main factors responsible for the poor survival (Preece and Sutter, 1991). In vitro-cultured plantlets are characterized by a thin cuticle (Grout, 1975; Sutter and Langhans, 1979), with different stomata1 morphology from those developed in the greenhouse or field (Donnelly and Vidaver, 1984; Wetzstein and Sommer, 1983) and stomatal malfunction (Marin et al., 1988). The amount of water lost over $24 \mathrm{~h}$ can be equivalent to two to three times the initial weight of the plantlets (Shackel et al., 1990). With no exception, all species of in vitro-cultured plantlets examined are somewhat susceptible to water stress. However, there is a large variation in their photosynthetic capacity, depending on the species. For this reason, Grout (1988) regrouped in vitro-cultured plantlets into two discrete classes, according to their photosynthetic capability. In the first class, leaves formed in vitro do not develop a photosynthetic capability if they grow on a sucrose containing medium. In the second class, leaves adapt to autotrophic conditions in vitro, and can have a significant photosynthetic rate. However, the differences between photosynthetic rates of in vitro plantlets may be attributed not only to inherent species-specific differences, but also to the methods used to measure photosynthesis (Preece and Sutter, 1991). In fact, it is often difficult to measure the photosynthesis of small in vitro-cultured plantlets (Kozai, 1991).

Grout and Millam (1985) reported that strawberry leaves formed in vitro on medium containing sucrose had an overall low photosynthetic activity at transplanting or during acclimatization. They concluded that strawberry leaves formed in vitro function only as storage organs and serve as a source of nutrient for new developing leaves. Accordingly, larger in vitro leaves may improve acclimatization success by increasing the quantity of reserves. Strawberry has been described as representative of the species in the first class

Received for publication 6 Apr. 1992. Accepted for publication 24 Oct. 1992. Paper no. CRH-59. We gratefully acknowledge Agriculture Canada and Conseil de la recherche en pêcheries et alimentation du Québec (CORPAQ) for their financial support. We also acknowledge Michael E.D. Graham and Jeffrey Norrie for their helpful technical support. The cost of publishing this paper was defrayed in part by the payment of page charges. Under postal regulations, this paper therefore must be hereby marked advertisement solely to indicate this fact.

${ }^{1}$ To whom reprint requests should be addressed. Present address: Centre de recherche en biologie forestière, Département des sciences forestières, Faculté de foresterie et de géomatique, Université Laval, Québec, G1K 7P4, Canada. in which the in vitro leaves do not develop a photosynthetic capacity (Grout, 1988). However, Kozai et al. (1989) showed that $\mathrm{CO}_{2}$ enrichment and high light level during culture could promote growth of plantlets, and that strawberry plantlets cultured on medium with or without sucrose could have positive photosynthetic activity. Desjardins et al. (1987) reported that $\mathrm{CO}_{2}$ enrichment and supplementary lighting during acclimatization had a positive effect on the growth of strawberry plantlets, although they did not determine the photosynthetic rates of in vitro leaves. Reexamination of the photosynthetic activity of strawberry is worthwhile because the evaluation of photosynthetic capacity is important in determining an appropriate set of light and gas conditions for in vitro culture and acclimatization. In this experiment, we designed an open gas exchange system and an assimilation chamber for plantlets, and measured the photosynthesis of in vitrocultured strawberry plantlets.

\section{Materials and methods}

Plant material and design of experiment. Strawberry shoots ('Kent') were cultured according to the method described by Desjardins et al. (1987). Auxiliary shoots (fresh weight $\approx 30 \mathrm{mg}$ ) were excised from plantlets that had been subcultured in a proliferation medium (Kartha et al., 1980) for 4 weeks and rooted in onehalf strength MS salts (Murashige and Skoog, 1962) with $0.12 \mu \mathrm{M}$ thiamine- $\mathrm{HCl}, 0.56 \mu \mathrm{M}$ myo-inositol, $30 \mathrm{~g}$ sucrose/liter, and $8 \mathrm{~g}$ Difco Bacto-agar/liter, and no growth regulators. The rooting medium was adjusted to $\mathrm{pH} 5.8$ and autoclaved at $1.4 \mathrm{~kg} \cdot \mathrm{cm}^{-2}$ and $121 \mathrm{C}$ for $15 \mathrm{~min}$. Five shoots were rooted in each $400-\mathrm{ml}$ polycarbonate culture vessel containing $50 \mathrm{ml}$ medium. Cultures were maintained in a growth room at $23 \pm 1 \mathrm{C}$ under a photosynthetic photon flux (PPF) of $60 \mu \mathrm{mol} \cdot \mathrm{m}^{-2} \cdot \mathrm{s}^{-1}$ for a photoperiod of $16 \mathrm{~h}$ provided by cool-white fluorescent lamps.

From the 2nd to the 4th week in rooting medium, 15 plantlets were sampled weekly. Growth characteristics measured included the number of leaves, leaf area, and fresh weight of plantlets. At the same time, five plantlets were used for the measurement of photosynthetic rate. Thirty plantlets were washed free of agar, transferred to a Pro-mix BX medium (Premier Peatmoss, Rivièredu-Loup, QC) in 150-ml Jiffy-pots (Jiffy Products, Batavia, Ill.) and grown in a greenhouse under the following conditions: temperature $26 / 22 \mathrm{C}$ (day/night); relative humidity $45 \%$ to $60 \%$; and PPF at plant level, $350 \mu \mathrm{mol} \cdot \mathrm{m}^{-2} \cdot \mathrm{s}^{-1}$. In the first week, plantlets 

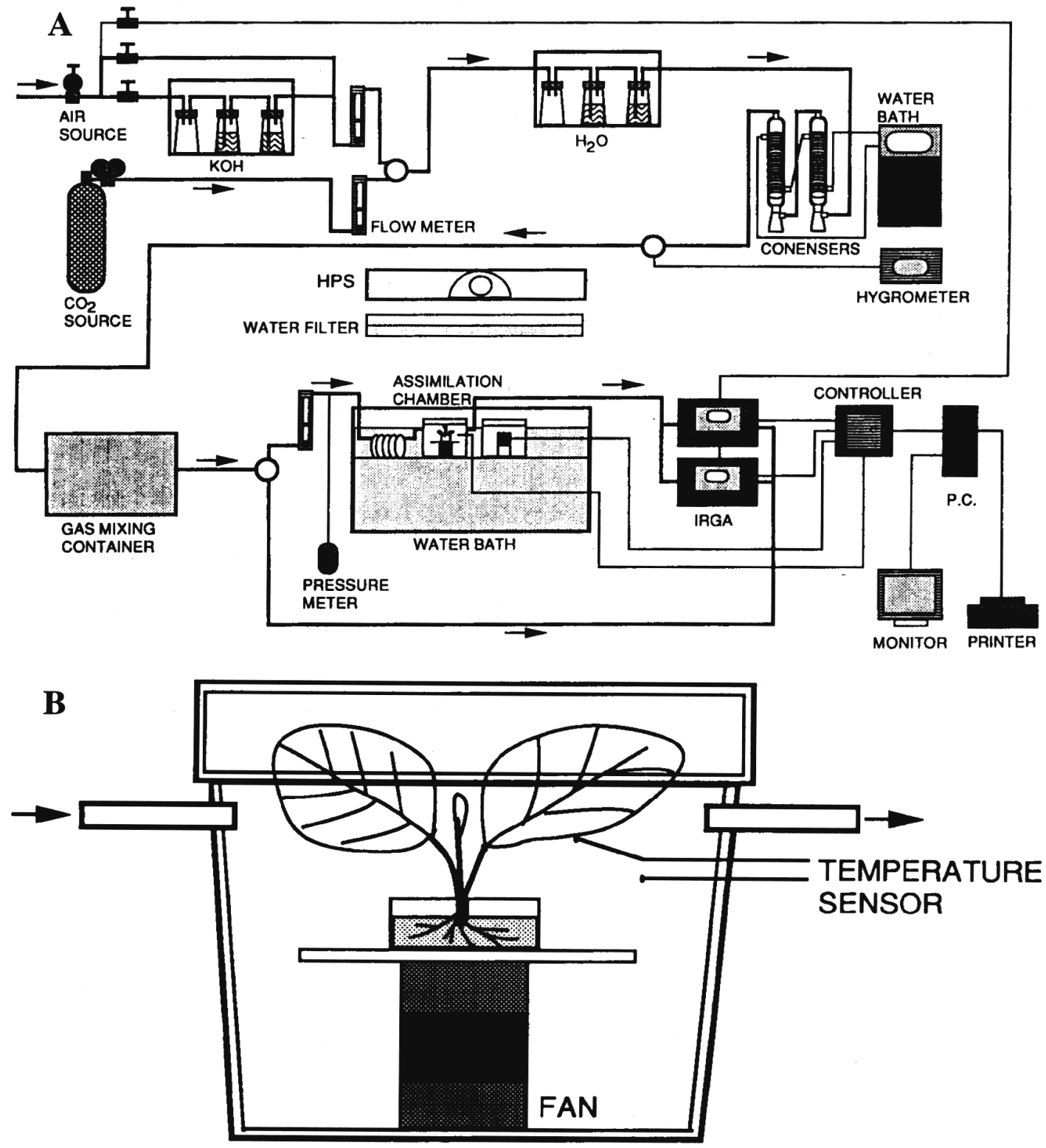

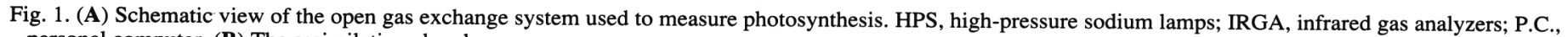
personal computer. (B) The assimilation chamber.

were watered once every day with $\approx 30 \mathrm{ml}$ water. Subsequently, they were watered and fertilized once every 2 days with $20 \mathrm{ml}$ of a solution containing N-P-K at a ratio of 150-150-250 mg.liter ${ }^{-1}$. The experiment lasted 8 weeks after the shoots were transferred onto the rooting medium. Growth characteristics and photosynthetic rates of plantlets in the greenhouse were again measured at the end of the experimental period.

A more detailed investigation on growth and photosynthesis after transfer to the greenhouse was carried out with plantlets cultured in rooting medium for 4 weeks. Plantlets having four in vitro formed leaves were selected, and the leaves were grouped according to their origin: i.e., group 1, first and second in vitro leaves (counted from the base in the order of initiation) with the age of 3 to 4 weeks old at the time of transplanting; group 2, the third and fourth in vitro leaves, 1 to 2 weeks old at the time of transplanting; and group 3, leaves formed during the ex vitro period. The growth characteristics and photosynthetic rates of each group of leaves were measured at transplanting (for group 1 and 2), and at the end of the first, second, and last weeks of the ex vitro period.

Plantlets with a single shoot were used in the study. The experiment was arranged in a completely randomized design.

To compare the photosynthetic rates of in vitro-generated leaves with that of ex vitro-generated leaves, plantlets cultured in rooting medium for 4 weeks were prepared and grown in the greenhouse for 12 weeks. The photosynthetic measurements were carried out on most recently fully expanded leaves of five plants.

Measurement of photosynthesis. Photosynthesis was measured using an open gas exchange system (Fig. 1) that was developed for the present experiment from a system described previously (Yue 
Table 1. Growth of in vitro-cultured strawberry plantlets after transfer to the ex vitro environment. Mean $\pm S E, n=15$.

\begin{tabular}{|c|c|c|c|c|c|c|c|}
\hline \multirow{2}{*}{$\begin{array}{l}\text { Duration } \\
\text { in rooting } \\
\text { medium } \\
\text { (wks) }\end{array}$} & \multirow{2}{*}{$\begin{array}{l}\text { Duration } \\
\text { in } \\
\text { greenhouse } \\
\text { (wks) }\end{array}$} & \multirow[b]{2}{*}{$\begin{array}{c}\text { No. } \\
\text { of leaves }\end{array}$} & \multicolumn{4}{|c|}{ Leaf area $\left(\mathrm{cm}^{2}\right)$} & \multirow{2}{*}{$\begin{array}{l}\text { Fresh wt } \\
\text { of plantlet } \\
\text { (mg) }\end{array}$} \\
\hline & & & $\begin{array}{l}\text { 1st \& 2nd } \\
\text { in vitro leaves }\end{array}$ & $\begin{array}{c}\text { 3rd \& 4th } \\
\text { in vitro leaves }\end{array}$ & $\begin{array}{l}\text { ex vitro } \\
\text { leaves }\end{array}$ & Total & \\
\hline \multirow[t]{2}{*}{2} & 0 & $2.5 \pm 0.2$ & $--^{y}$ & --- & --- & $0.62 \pm 0.05$ & $35 \pm 2$ \\
\hline & 6 & $4.5 \pm 0.1$ & --- & --- & --- & $12.96 \pm 0.25$ & $808 \pm 57$ \\
\hline \multirow[t]{2}{*}{3} & 0 & $3.3 \pm 0.2$ & --- & --- & --- & $1.50 \pm 0.12$ & $75 \pm 5$ \\
\hline & 5 & $5.3 \pm 0.1$ & --- & --- & --- & $14.56 \pm 1.21$ & $639 \pm 50$ \\
\hline \multirow[t]{4}{*}{4} & 0 & $4.2 \pm 0.1$ & $0.98 \pm 0.08$ & $1.72 \pm 0.14$ & 0.00 & $2.70 \pm 0.21$ & $125 \pm 11$ \\
\hline & 1 & $4.8 \pm 0.1$ & $1.07 \pm 0.09$ & $2.19 \pm 0.17$ & $0.54 \pm 0.12$ & $3.80 \pm 0.28$ & $145 \pm 9$ \\
\hline & 2 & $5.7 \pm 0.1$ & $1.18 \pm 0.06$ & $3.45 \pm 0.25$ & $3.54 \pm 0.51$ & $8.17 \pm 0.53$ & $290 \pm 12$ \\
\hline & 4 & $6.6 \pm 0.2$ & $1.38 \pm 0.18$ & $4.00 \pm 0.33$ & $14.06 \pm 0.91$ & $19.45 \pm 1.08$ & $890 \pm 54$ \\
\hline \multicolumn{8}{|c|}{ Significance } \\
\hline \multicolumn{2}{|c|}{ Duration in rooting medium (A) } & $* *$ & & & & NS & NS \\
\hline \multicolumn{2}{|c|}{ Duration in greenhouse (B) } & NS & NS & $* *$ & $* *$ & $* *$ & $* *$ \\
\hline \multicolumn{2}{|c|}{$A \times B$} & $* *$ & & & & $* *$ & $* *$ \\
\hline
\end{tabular}

${ }^{\mathrm{z} C o u n t e d}$ in the order of initiation.

y Data not available.

Ns,*** Nonsignificant or significant at $\mathrm{P}=0.01$, respectively.

et al., 1992). In the system (Fig. 1A), outdoor air was brought in through an outside line, and $\mathrm{CO}_{2}$ in the air was absorbed by bubbling through $\mathrm{KOH}$ solution. The $\mathrm{CO}_{2}$-free air was mixed with $\mathrm{CO}_{2}$ from a cylinder $\left(0.5 \% \quad \mathrm{CO}_{2}\right.$ in $\left.\mathrm{N}_{2}\right)$. This mixture was then moistened by bubbling through flasks containing water, and the humidity was adjusted by the condensers connected to a water bath. A hydrometer (model 91, Yellow Springs Instrument Co., Yellow Springs, Ohio) was used to monitor the humidity. To increase the stability of $\mathrm{CO}_{2}$ concentration and humidity, air was sent to a 10-liter gas mixing container before being sent to the reference sides of two infrared gas analyzers (ADC MK225, Hoddsdon, England) and an analysis line that led to the assimilation chamber. Differential modes of the infrared gas analyzers were used for measurements of $\mathrm{CO}_{2}$ concentration and water vapor pressure, respectively. Air flow rate was controlled by a highresolution flowmeter (N-03227- 18, Cole-Palmer Instrument Co., Chicago, Ill.) and the pressure in this part of the air circulation system was measured using a digital electronic pressure meter (KM5002, Kane-May, Welwyn Garden City, Hertfordshire). Air temperature was adjusted before the air entered the assimilation chamber using a coil made of copper pipe submerged in a water bath. Part of the assimilation chamber was also submerged in the water bath to keep the temperature stable. Lighting of the chamber was supplied by three 400-W high-pressure sodium vapor lamps (400-SO, Lumiponic, Montreal) suspended above a $3.5 \mathrm{~cm}$ deep water filter. PPF at the leaf level was varied by changing the distance between the lamps and the assimilation chamber. Signals from the infrared gas analyzers, the temperature sensors, and the light sensor were sent to a controller (MT1000, Measurement Technology, Stoughton, Mass.) and then to a computer. All variables, including changes in $\mathrm{CO}_{2}$ concentration, water vapor pressure, PPF, and temperature were monitored on adisplay. Data were written onto a diskette and printed by the computer.

The assimilation chamber (Fig. 1B) was a 400-ml polycarbonate culture vessel. Two holes were made for the inlet and outlet air, respectively. High vacuum grease (Dow Coming Canada, Mississauga, Ont.) was used to help seal the cap on the culture vessel. There was a brushless micro cooling fan (model 273-244, Radio Shack, Fort Worth, Texas) on the bottom that mixed the air inside the chamber. Leaf temperature and the air temperature inside the chamber were measured using two thermocouple sen- sors (9B1B8, Minneapolis-Honeywell Regulator Co., Philadelphia). A light sensor (Q9975, LICOR, Lincoln, Neb.) was placed in another culture vessel beside the assimilation chamber at leaf level to measure PPF. During measurements, the air temperature inside the assimilation chamber was maintained at $25 \pm 0.5 \mathrm{C}$. Relative humidity of the inlet air at this temperature was $80 \% \pm 3 \%$. The $\mathrm{CO}_{2}$ concentration of the inlet air was $385 \pm 3 \mu \mathrm{l} \cdot \mathrm{liter}^{-1}$. Air flow through the assimilation chamber was changed between 500 and $800 \mathrm{ml} \cdot \mathrm{min}-1$, according to leaf size. The roots and medium were placed into a small plastic tube, coated with parafilm, and sealed with high vacuum grease. When photosynthesis of certain leaves was to be measured, other leaves were cut off and the traces were sealed with high vacuum grease. The plantlet was then placed in the assimilation chamber. Data were taken when the $\mathrm{CO}_{2}$ concentration and water vapor pressure became stable. When PPF was changed, measurements were first made at high PPF followed by sequentially lower light levels.

Photosynthesis of the leaves generated and grown in the greenhouse was measured using a standard assimilation chamber. Other conditions remained unchanged, except for the air flow rate that was increased to $3400 \mathrm{ml} \cdot \mathrm{min}^{-1}$.

The gas exchange data were calculated according to Long and Hallgren (1985) and Moon and Flore (1986). All factors that affect the results, including temperature, air pressure, air flow rates, leaf area, change in $\mathrm{CO}_{2}$ concentration, and water vaporpressure inside the assimilation chamber were considered in the calculations.

\section{Results}

Growth of plantlets during in vitro culture and growing in the greenhouse. Most shoots rooted within 10 days of culture in the rooting medium. Two weeks after culture in the rooting medium, at the time of the first transfer to the greenhouse, the plantlets had 1 to 3 roots, with two or three expanded leaves having a total leaf area of $0.62 \pm 0.05 \mathrm{~cm}^{2}$; the fresh weight was $35 \pm 2 \mathrm{mg}$ (Table 1). After 4 weeks of culture in the rooting medium, the average leaf area was $2.7 \mathrm{~cm}^{2}$ and the fresh weight was $125 \mathrm{mg}$.

All plantlets survived in the greenhouse. At the end of the experiment, the largest leaf area was measured for plantlets cultured in rooting medium for 3 weeks, but the highest fresh weight was measured for plantlets cultured in rooting medium for 2 
weeks. Plantlets cultured in rooting medium for 4 weeks initiated an average of 2.4 leaves during the ex vitro period. Increase in leaf area of first and second leaves that formed in vitro was not statistically significant. However, the third and fourth leaves formed in vitro expanded from 1.72 to $4.00 \mathrm{~cm}^{2}$, increasing by $133 \%$. New leaves appeared during the first week of the ex vitro period, but greater expansion occurred in the last 2 weeks of the ex vitro period.

Photosynthetic rates of whole plantlets. The average net photosynthetic rate of plantlets was $6.62 \mu \mathrm{mol} \mathrm{CO}_{2} / \mathrm{m}^{2}$ per sec after culture in rooting medium for 2 weeks (Table 2). This rate increased to $>12 \mu \mathrm{mol} \mathrm{CO} / \mathrm{m}^{2}$ per sec after 3 weeks of culture in rooting medium, and then remained at this level until the end of the in vitro period. With plantlets cultured in rooting medium for 4 weeks, net photosynthesis dropped to $7.36 \mu \mathrm{mol} \mathrm{CO} / \mathrm{C}_{2}^{2}$ per sec in the 2 nd week of the ex vitro period, and then increased back to the original rates after growing in the greenhouse for 4 weeks. At transplanting, the lowest dark respiration rates were measured for plantlets cultured in rooting medium for 4 weeks. At the end of the experiment, no differences in net photosynthesis or gross photosynthesis were found among plantlets cultured in rooting medium for different durations.

Under PPF of 2.50 to $3.50 \mu \mathrm{mol} \cdot \mathrm{m}^{-2} \cdot \mathrm{s}^{-1}$, all plantlets measured in the experiment exhibited similar rates of net photosynthesis (Fig. $2)$. However, under $\mathrm{PPF}<200 \mu \mathrm{mol} \cdot \mathrm{m}^{-2} \cdot \mathrm{s}^{-1}$, in vitro-cultured plantlets at transplanting had higher photosynthetic rates than those grown in the greenhouse for 4 weeks. Leaves of the plants that had been grown in the greenhouse for 12 weeks had the lowest rates.

Photosynthesis of leavesformed in vitro and ex vitro. At the end of in vitro culture, the first and second leaves that were formed in vitro had a net photosynthetic rate of $6.69 \mu \mathrm{mol} \mathrm{CO}_{2} / \mathrm{m}^{2}$ per sec

Table 2. Photosynthetic capacity of strawberry plantlets after transfer to ex vitro environment. Measurements were carried out under PPF of $350 \mu \mathrm{mol} \cdot \mathrm{m}^{-2} \cdot \mathrm{s}^{-1}$. Mean $\pm \mathrm{SE}, \mathrm{n}=5$.

\begin{tabular}{|c|c|c|c|c|}
\hline $\begin{array}{l}\text { Duration in } \\
\text { rooting medium } \\
\text { (wks) }\end{array}$ & $\begin{array}{c}\text { Duration in } \\
\text { greenhouse } \\
(w k s)\end{array}$ & $\begin{array}{c}\text { Net photosynthesis } \\
\left(\mu \mathrm{mol} \mathrm{CO} \mathrm{CO}_{2} / \mathrm{m}^{2} \text { per sec }\right)\end{array}$ & $\begin{array}{c}\text { Dark respiration } \\
\left(\mu \mathrm{mol} \mathrm{CO}_{2} / \mathrm{m}^{2} \text { per sec }\right)\end{array}$ & $\begin{array}{l}\text { Gross photosynthesis } \\
\left(\mu \mathrm{mol} \mathrm{CO}_{2} / \mathrm{m}^{2} \text { per sec) }\right.\end{array}$ \\
\hline \multirow[t]{2}{*}{2} & 0 & $6.62 \pm 1.01$ & $1.65 \pm 0.35$ & $8.27 \pm 0.88$ \\
\hline & 6 & $12.26 \pm 0.42$ & $2.16 \pm 0.13$ & $14.42 \pm 0.29$ \\
\hline \multirow[t]{2}{*}{3} & 0 & $12.26 \pm 1.82$ & $2.16 \pm 0.22$ & $14.42 \pm 1.96$ \\
\hline & 5 & $12.72 \pm 0.49$ & $2.45 \pm 0.04$ & $15.17 \pm 0.46$ \\
\hline \multirow[t]{4}{*}{4} & 0 & $12.76 \pm 0.70$ & $0.97 \pm 0.16$ & $13.73 \pm 0.62$ \\
\hline & 1 & $12.03 \pm 0.97$ & $1.24 \pm 0.17$ & $13.27 \pm 1.13$ \\
\hline & 2 & $7.36 \pm 0.94$ & $1.49 \pm 0.13$ & $8.85 \pm 0.87$ \\
\hline & 4 & $12.53 \pm 1.25$ & $1.51 \pm 0.34$ & $14.05 \pm 1.41$ \\
\hline \multicolumn{5}{|l|}{ Significance } \\
\hline \multirow{2}{*}{\multicolumn{2}{|c|}{$\begin{array}{l}\text { Duration in rooting medium (A) } \\
\text { Duration in greenhouse }(\mathrm{B})\end{array}$}} & $*$ & * & * \\
\hline & & $*$ & NS & $*$ \\
\hline \multicolumn{2}{|c|}{$\mathrm{A} \times \mathrm{B}$} & NS & NS & NS \\
\hline
\end{tabular}

Table 3. Photosynthetic rates of strawberry leaves generated and grown under different conditions. Measurements were carried out under PPF of $350 \mu \mathrm{mol} \cdot \mathrm{m}^{-2} \cdot \mathrm{s}^{-1}$. Mean $\pm \mathrm{SE}, \mathrm{n}=5$.

\begin{tabular}{|c|c|c|c|c|}
\hline $\begin{array}{c}\text { Duration in } \\
\text { greenhouse } \\
\text { (wks) }\end{array}$ & Leaves $^{\mathrm{z}}$ & $\begin{array}{c}\text { Net photosynthesis } \\
\left(\mu \mathrm{mol} \mathrm{CO} \mathrm{CO}_{2} / \mathrm{m}^{2} \text { per sec }\right)\end{array}$ & $\begin{array}{c}\text { Dark respiration } \\
\left(\mu \mathrm{mol} \mathrm{CO} \mathrm{CO}_{2} / \mathrm{m}^{2} \text { per sec }\right)\end{array}$ & 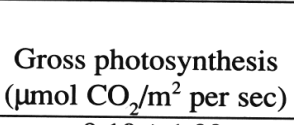 \\
\hline \multirow[t]{2}{*}{0} & 1st \& 2nd IVL & $6.69 \pm 1.58$ & $2.41 \pm 0.63$ & $9.10 \pm 1.29$ \\
\hline & 3rd \& 4th IVL & $13.37 \pm 0.42$ & $0.76 \pm 0.19$ & $14.13 \pm 0.46$ \\
\hline \multirow[t]{3}{*}{1} & 1st \& 2nd IVL & $9.61 \pm 1.80$ & $2.86 \pm 0.57$ & $12.47 \pm 2.36$ \\
\hline & 3rd \& 4th IVL & $11.67 \pm 2.26$ & $1.72 \pm 0.39$ & $13.39 \pm 2.49$ \\
\hline & EVL & $6.99 \pm 1.83$ & $4.79 \pm 1.13$ & $11.78 \pm 2.12$ \\
\hline \multirow[t]{3}{*}{2} & 1st \& 2nd IVL & $3.49 \pm 0.87$ & $4.52 \pm 0.62$ & $8.01 \pm 0.80$ \\
\hline & 3rd \& 4th IVL & $7.89 \pm 1.09$ & $2.16 \pm 0.50$ & $10.05 \pm 0.88$ \\
\hline & EVL & $7.31 \pm 1.33$ & $3.30 \pm 0.58$ & $10.61 \pm 1.64$ \\
\hline \multirow[t]{3}{*}{4} & 1st \& 2nd IVL & $-1.02 \pm 1.10$ & $6.70 \pm 0.92$ & $5.68 \pm 0.39$ \\
\hline & 3rd \& 4th IVL & $5.11 \pm 1.64$ & $3.42 \pm 0.43$ & $8.53 \pm 1.36$ \\
\hline & EVL & $13.10 \pm 2.98$ & $2.79 \pm 3.22$ & $15.89 \pm 6.16$ \\
\hline Greenhouse-gro & leaves ${ }^{y}$ & $12.40 \pm 0.70$ & $0.52 \pm 0.05$ & $12.92 \pm 0.88$ \\
\hline \multicolumn{5}{|c|}{ Significance } \\
\hline \multicolumn{2}{|l|}{ Duration in } & $* *$ & NS & $*$ \\
\hline \multicolumn{2}{|l|}{ Leaves (B) } & $*$ & $*$ & NS \\
\hline \multicolumn{2}{|l|}{$\mathrm{A} \times \mathrm{B}$} & $* *$ & $* *$ & NS \\
\hline
\end{tabular}

${ }^{\mathrm{z}} 1 \mathrm{st} \&$ 2nd IVL $=$ first and second in vitro leaves (counted in the order of initiation); 3rd \& 4th IVL $=$ third and fourth in vitro leaves; $E V L=$ ex vitro leaves.

${ }^{y}$ Leaves of the plants grown in the greenhouse for 12 weeks.

Ns, ${ }^{* * *}$ Nonsignificant or significant at $P=0.05$ or 0.01 , respectively. 
(Table 3). During the first week of the ex vitro period, the rate increased to $9.61 \mu \mathrm{mol} \mathrm{CO} / \mathrm{m}^{2}$ per sec. It decreased to 3.49 in the 2nd week, then to $-1.02 \mu \mathrm{mol} \mathrm{CO} / \mathrm{m}^{2}$ per sec at the end of ex vitro period. The dark respiration of these leaves increased gradually from $2.41 \mu \mathrm{mol} \mathrm{CO}_{2} / \mathrm{m}^{2}$ per sec immediately after transfer to the greenhouse to $6.70 \mu \mathrm{mol} \mathrm{CO} / \mathrm{m}^{2}$ per sec at the end of the experimental period.

For the third and fourth leaves formed in vitro, the highest photosynthetic rate of $13.37 \mu \mathrm{mol} \mathrm{CO}_{2} / \mathrm{m}^{2}$ per sec was found at the end of in vitro period. The rate decreased to $5.11 \mu \mathrm{mol} \mathrm{CO} / \mathrm{m}^{2}$ per $\mathrm{sec}$ at the end of the ex vitro period. The same trend was observed for gross photosynthesis. Dark respiration rates of these leaves increased gradually during the ex vitro period.

The net photosynthesis of ex vitro formed leaves was $-7 \mu \mathrm{mol}$ $\mathrm{CO}_{2} / \mathrm{m}^{2}$ per sec when they were expanding during the first and $2 \mathrm{nd}$ weeks of the ex vitro period. At the end of the ex vitro period, the rate increased to $13.1 \mu \mathrm{mol} \mathrm{CO}_{2} / \mathrm{m}^{2}$ per sec. The highest gross photosynthesis was also found at this time. Dark respiration decreased during the ex vitro period.

Net photosynthesis and gross photosynthesis measured at a PPF of $350 \mu \mathrm{mol} \cdot \mathrm{m}^{-2} \cdot \mathrm{s}^{-1}$ for leaves formed in vitro and ex vitro, closely approximated with those plants that had been grown in the greenhouse for 12 weeks.

\section{Discussion}

The photosynthetic capacity of strawberry leaves formed in vitro, on medium containing sucrose, appears to be quite normal. After 2 weeks of culture in rooting medium, when the leaves were still young and the total leaf area was only $0.62 \mathrm{~cm}^{2}$ (Table 1), their net photosynthetic rate had reached a level of $6.62 \mu \mathrm{mol} \mathrm{CO} \mathrm{C}_{2} / \mathrm{m}^{2}$ per sec. This was $\approx 50 \%$ of the rate found for leaves generated and grown in the greenhouse (Table 3). After this time, the leaves expanded and the photosynthetic rate increased to a level as high as that of leaves generated and grown in the greenhouse. Under low PPF conditions, such as those encountered during in vitro culture and acclimatization, leaves formed in vitro had the same or higher photosynthetic rates than leaves generated and grown in the greenhouse (Fig. 2). After removal from in vitro culture, the photosynthetic rates decreased, while dark respiration increased from the 2nd week. However, leaves generated in vitro developed a positive photosynthetic capacity, which remained significant after transfer to the ex vitro environment. Net photosynthesis was still positive at the end of the 2 nd week of the ex vitro period for the first and second leaves formed in vitro, while net photosynthesis was positive throughout the entire ex vitro period for third and fourth leaves formed in vitro.

Our data showed that in vitro-cultured strawberry plantlets can grow autotrophically throughout the 4-week ex vitro period. With plantlets cultured in rooting medium for 4 weeks, in the 2 nd week the net photosynthesis of in vitro-formed leaves had decreased, while the net photosynthesis of newly formed leaves was at a low level (Table 3). By this time, photosynthesis of in vitro-formed leaves was still sufficient to support autotrophic growth. These data indicate that photosynthesis carried out by leaves formed in vitro would allow for autotrophic growth during the first 2 weeks of the ex vitro period. In the first week of the ex vitro period, when the ex vitro leaves had a small leaf area ( $14 \%$ of total leaf area, Table 1) and their photosynthetic rate was lower than that of in vitro leaves (Table 3), in vitro leaves contributed most to total photosynthesis of the plantlets. In the 2 nd week of the ex vitro period, when ex vitro leaves expanded and their photosynthetic rate increased, in vitro leaves were still contributing $>50 \%$ to total photosynthesis.
These results are in opposition to those published by Grout and Millam (1985). Indeed, data shown in Table 1 and 3 suggest that photosynthesis carried out by leaves formed in vitro plays an important role in supporting the expansion of both ex vitro and in vitro-formed leaves and normal growth of whole plantlets (Table 1). In the present experiment, plantlets cultured in rooting medium for 2 weeks, with a leaf area of $0.62 \mathrm{~cm}^{2}$, grew as well as those with larger leaves cultured in a rooting medium for 3 or 4 weeks. This fact did not coincide with the hypothesis by Grout and Millam (1985) that larger in vitro leaves may improve the acclimatization success because of higher reserves. These contrasting results may have been caused by differences in methodology and plant material. In the experiment reported by Grout and Millam (1985), plantlets transferred into vermiculite in glass pots were sealed with polyethylene bags for $3 \mathrm{~h}$. The fixation of ${ }^{14} \mathrm{C}$ during this period was used to evaluate the photosynthetic capacity. Kozai et al. (1989) measured photosynthesis using a system designed with forced ventilation. In the present experiment, we have used a very precise system for the measurement of photosynthesis for in vitrocultured plantlets. Different cultivars were used in the experiment reported by Grout and Millam (1985) and our experiment. However, there should not be big differences in photosynthetic capacity among these cultivars because photosynthetic rates among cultivars are similar (Hancock et al., 1989).

In conclusion, strawberry leaves formed in vitro on medium containing sucrose are able to photosynthesize under in vitro and ex vitro conditions. The leaves formed in vitro may function as a source of nutrients for expanding leaves newly formed ex vitro, but they also play an important role in photosynthesis, thereby promoting the autotrophic growth of plantlets. More successful in vitro culture and acclimatization may be realized if the photosynthetic capacity of the leaves formed in vitro is used to its maximum potential.

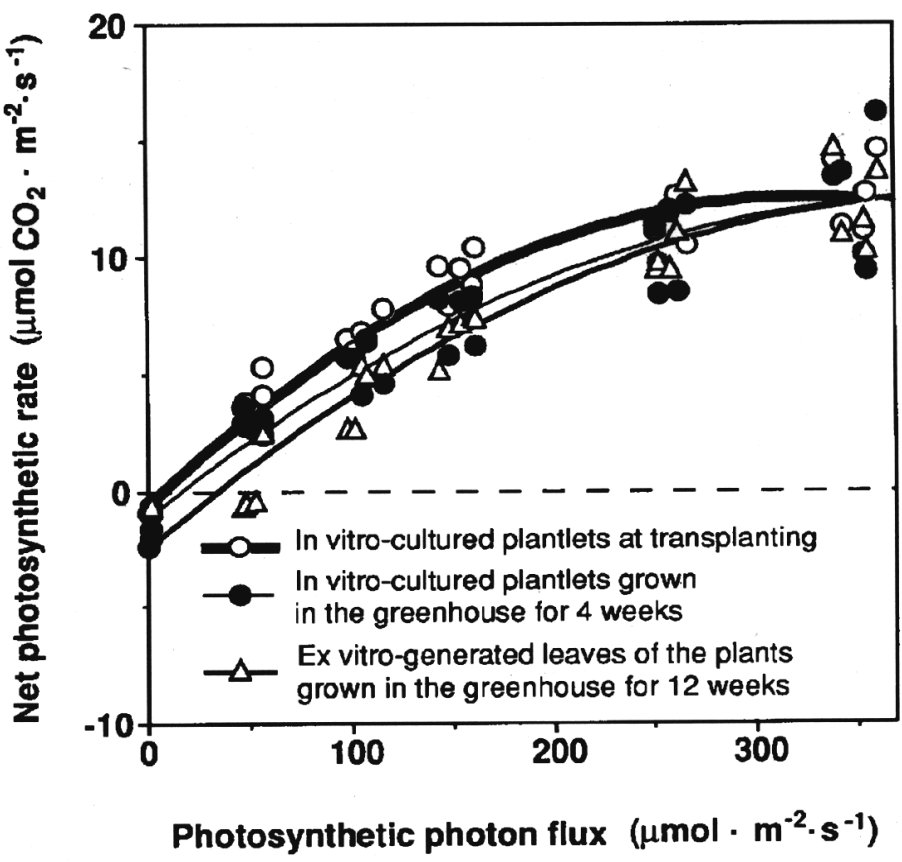

Fig. 2. Net photosynthetic rates of in vitro-cultured plantlets and ex vitro-generated leaves of the plants that had grown in the greenhouse for 12 weeks. The equation to predict photosynthetic rate of in vitro-cultured plantlets at transplanting as a function of PPF is $\mathrm{Y}=-0.599+0.0815 \mathrm{X}-0.000127 \mathrm{X}^{2}, R^{2}=0.956, P<0.001$; for in vitro cultured plantlets grown in the greenhouse for 4 weeks the equation is $\mathrm{Y}=-1.090+0.0688 \mathrm{X}-0.0000870 \mathrm{X} 2, R^{2}=0.913, P<0.001$; for ex vitrogenerated leaves of the plants grown in the greenhouse for 12 weeks the equation is $\mathrm{Y}=-2.41+0.0730 \mathrm{X}-0.0000883 \mathrm{X}^{2}, R^{2}=0.922, P<0.001$. 


\section{Literature Cited}

Desjardins, Y., A. Gosselin, and S. Yelle, 1987. Acclimatization of ex vitro strawberry plantlets in $\mathrm{CO}_{2}$-enriched environments and supplementary lighting. J. Amer. Soc. Hort. Sci. 112:846-851.

Donnelly, D.J. and W.E. Vidaver. 1984. Leaf anatomy of red raspberry transferred from culture to soil. J. Amer. Soc. Hort. Sci. 109:172-176.

Grout, B.W.W. 1975. Wax development of leaf surfaces of Brassica oleracea var. Currawong regenerated from meristem culture. Plant Sci. Lett. 5:401-405.

Grout, B.W.W. 1988. Photosynthesis ofregenerated plantlets in vitro, and the stress of transplanting. Acta Hort. 230:129-135.

Grout, B.W.W. and S. Millam. 1985. Photosynthetic development of micropropagated strawberry plantlets following transplanting. Ann. Bot. 55:129-131.

Hancock, J.F., J.A. Flore, and G.J. Galletta. 1989. Variation in leaf photosynthetic rates and yield in strawberries. J. Hort. Sci. 64:449-454.

Kartha, K.K., N.L. Leung, and K. Pahl. 1980. Cryopreservation of strawberry meristems and mass propagation of plantlets. J. Amer. Soc. Hort. Sci. 105:481-484.

Kozai, T., 1991. Micropropagation under photoautotrophic conditions, p. 447-469. In: P.C. Debergh and R.H. Zimmerman (eds.). Micro-propagation, technology and application. Kluwer Academic Publ., Boston.

Kozai, T., C. Kubota; and M. Nakayama. 1989. Net photosynthetic rates of plantlets in vitro under natural and forced ventilation conditions. Abstr. Annu. Meeting Jpn. Soc. Hort. Sci. 1989:250-251.

Long, S.P. and J-E. Hallgren. 1985. Measurement of $\mathrm{CO}_{2}$ assimilation by plants in the field and the laboratory, p. 62-94. In: J. Loombs, D.O. Hall, S.P. Long, and J.M.O. Surlock (eds.). Techniques in bioproductivity and photosynthesis. Pergamon Press, Oxford, England.

Marin, J.A., R. Gella, and M. Herrero. 1988. Stomatal structure and functioning as a response to environmental changes in acclimatized micropropagated Prunus cerasus L. Ann. Bot. 62:663-670.

Moon J., Jr., and J.A. Flore. 1986. A basic computer program for calculation of photosynthesis, stomatal conductance, and related parameters in an open gas exchange system. Photosynthesis Res. 7:269-279.

Murashige, T. and F. Skoog. 1962. A revised medium for rapid growth and bio-assay with tobacco tissue cultures. Physiol. Plant. 15:473-497.

Preece, J.E. and E.G. Sutter. 1991. Acclimatization of micropropagated plants to the greenhouse and field, p. 71-93. In: P.C. Debergh and R.H. Zimmerman (eds.). Micropropagation, technology and application. Kluwer Academic Publ., Boston.

Shackel, K.A., V. Novello, and E.G. Sutter. 1990. Stomatal function and cuticular conductance in whole tissue cultured apple plants. J. Amer. Soc. Hort. Sci. 115:468-472.

Sutter, E. and R.W. Langhans. 1979. Epicuticular wax formation on carnation plantlets regenerated from shoot tip culture. J. Amer. Soc. Hort. Sci. 104:493-496.

Wetzstein, H.Y. and H.E. Sommer. 1983. Scanning electron microscopy of in vitro-cultured Liquidambar styraciflua plantlets during acclimatization. J. Amer. Soc. Hort. Sci. 108:475-480.

Yue, D., Y. Desjardins, M. Lamarre, and A. Gosselin. 1992. Photosynthesis and transpiration of in vitro-cultured asparagus plantlets. Scientia Hort. 49:9-16. 